Article

\title{
Antioxidant Mechanisms of Echinatin and Licochalcone A
}

\author{
Minshi Liang ${ }^{1,2,+}$, Xican Li ${ }^{1,2,+, * \mathbb{D}}$, Xiaojian Ouyang ${ }^{1,2}$, Hong Xie ${ }^{1,2}$ and Dongfeng Chen ${ }^{3,4, *}$ \\ 1 School of Chinese Herbal Medicine, Guangzhou University of Chinese Medicine, Guangzhou 510006, China; \\ lminshi@outlook.com (M.L.); oyxiaojian55@163.com (X.O.); xiehongxh1@163.com (H.X.) \\ 2 Innovative Research \& Development Laboratory of TCM, Guangzhou University of Chinese Medicine, \\ Guangzhou 510006, China \\ 3 School of Basic Medical Science, Guangzhou University of Chinese Medicine, Guangzhou 510006, China \\ 4 The Research Center of Basic Integrative Medicine, Guangzhou University of Chinese Medicine, \\ Guangzhou 510006, China \\ * Correspondence: lixc@gzucm.edu.cn (X.L.); chen888@gzucm.edu.cn (D.C.); \\ Tel.: +86-20-3935-8076 (X.L.); Fax: +86-20-3889-2690 (X.L.) \\ + These authors contributed equally to this work.
}

Academic Editors: Susana M. Cardoso and Alessia Fazio

Received: 3 December 2018; Accepted: 18 December 2018; Published: 20 December 2018

\begin{abstract}
Echinatin and its 1,1-dimethyl-2-propenyl derivative licochalcone A are two chalcones found in the Chinese herbal medicine Gancao. First, their antioxidant mechanisms were investigated using four sets of colorimetric measurements in this study. Three sets were performed in aqueous solution, namely $\mathrm{Cu}^{2+}$-reduction, $\mathrm{Fe}^{3+}$-reduction, and 2-phenyl-4,4,5,5-tetramethylimidazoline-1-oxyl 3-oxide radical (PTIO•)-scavenging measurements, while 1,1-diphenyl-2-picrylhydrazyl radical (DPPH•)-scavenging colorimetric measurements were conducted in methanol solution. The four sets of measurements showed that the radical-scavenging (or metal-reduction) percentages for both echinatin and licochalcone A increased dose-dependently. However, echinatin always gave higher $\mathrm{IC}_{50}$ values than licochalcone A. Further, each product of the reactions of the chalcones with DPPH• was determined using electrospray ionization quadrupole time-of-flight tandem mass spectrometry (UPLC-ESI-Q-TOF-MS/MS). The UPLC-ESI-Q-TOF-MS/MS determination for echinatin yielded several echinatin-DPPH adduct peaks $(\mathrm{m} / z$ 662, 226, and 196) and dimeric echinatin peaks $(\mathrm{m} / \mathrm{z}$ 538,417 , and 297). Similarly, that for licochalcone A yielded licochalcone A-DPPH adduct peaks $(m / z 730,226$, and 196) and dimeric licochalcone A peaks ( $m / z 674$ and 553). Finally, the above experimental data were analyzed using mass spectrometry data analysis techniques, resonance theory, and ionization constant calculations. It was concluded that, (i) in aqueous solution, both echinatin and licochalcone A may undergo an electron transfer (ET) and a proton transfer (PT) to cause the antioxidant action. In addition, (ii) in alcoholic solution, hydrogen atom transfer (HAT) antioxidant mechanisms may also occur for both. HAT may preferably occur at the 4-OH, rather than the $4^{\prime}-\mathrm{OH}$. Accordingly, the oxygen at the 4-position participates in radical adduct formation (RAF). Lastly, (iii) the 1,1-dimethyl-2-propenyl substituent improves the antioxidant action in both aqueous and alcoholic solutions.
\end{abstract}

Keywords: antioxidant; echinatin; licochalcone A; 1,1-dimethyl-2-propenyl; $\alpha, \alpha$-dimethyl- $\beta$-propenyl; radical adduct formation; dimer

\section{Introduction}

Echinatin and licochalcone A (Figure 1) are two chalcones in the Chinese herbal medicine Gancao (Glycyrrhizae radix et rhizoma) [1,2]. A recent study suggested that both chalcones can be absorbed by 
human Caco-2 monolayer cells after the oral administration of Gancao [3]. However, pure echinatin and licochalcone A have been shown to exhibit hepatoprotective [4] and anti-inflammatory effects [5,6]. These pharmacological effects are known to be closely associated with antioxidant action $[7,8]$. A literature survey revealed that no relevant studies have focused on the antioxidant effects (or mechanisms) of echinatin or licochalcone A; thus, it is necessary to conduct such a study. In this study, the antioxidant potentials of the 4-OH and $4^{\prime}-\mathrm{OH}$ groups in each chalcone molecule were compared for the first time.

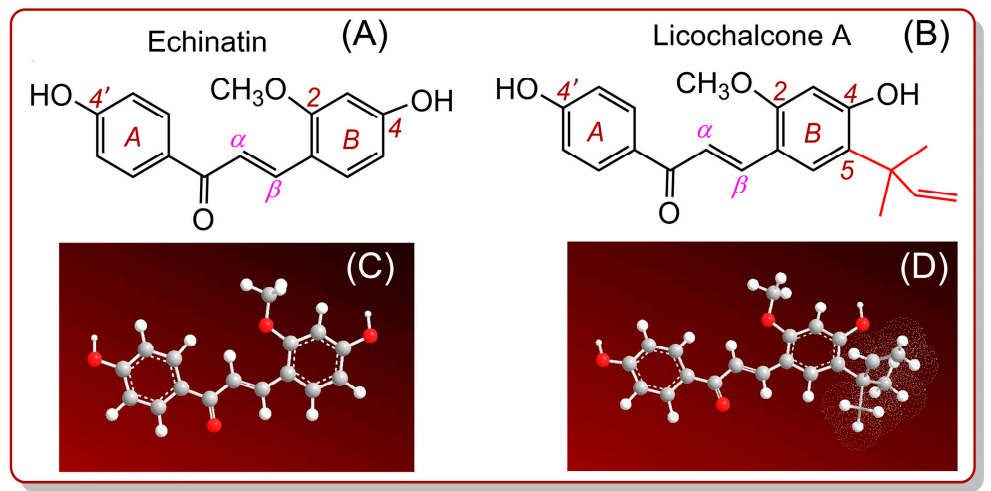

Figure 1. Structural formulas and molecular models of echinatin and licochalcone A: A, structural formula of echinatin; B, structural formula of licochalcone A; C, preferential conformation-based molecular model of echinatin; and $\mathbf{D}$, preferential conformation-based molecular model of licochalcone A. The molecular models were created based on molecular mechanics calculations using Chem3D Pro 14.0. (red, O; gray, C; white, H).

As shown in Figure 1, echinatin and licochalcone A both bear a $4^{\prime}$-OH group in the $A$ ring, and a 4-OH group in the $\mathrm{B}$ ring. These two phenolic $-\mathrm{OH}$ groups possess similar but different chemical environments (Figure 1). Similar situations can also be found in other chalcones and isoflavones, such as licochalcone C (2a, Figure 2), corylifol A (2b, Figure 2), 2'-O-methylisoliquiritigenin, oureirin A, daidzein, daidzin, 7,4'-di-O-methyldaidzein, 8-prenyldaidzein, 3'-methoxypuerarin, $4^{\prime}$-methoxypuerarin, and isoformononetin (Supplementary File 1). However, whether there is a difference in the antioxidant abilities of the two phenolic-OHs remains unknown [9-12]. Therefore, the present study will also deepen our understanding of these chalcones and isoflavones.

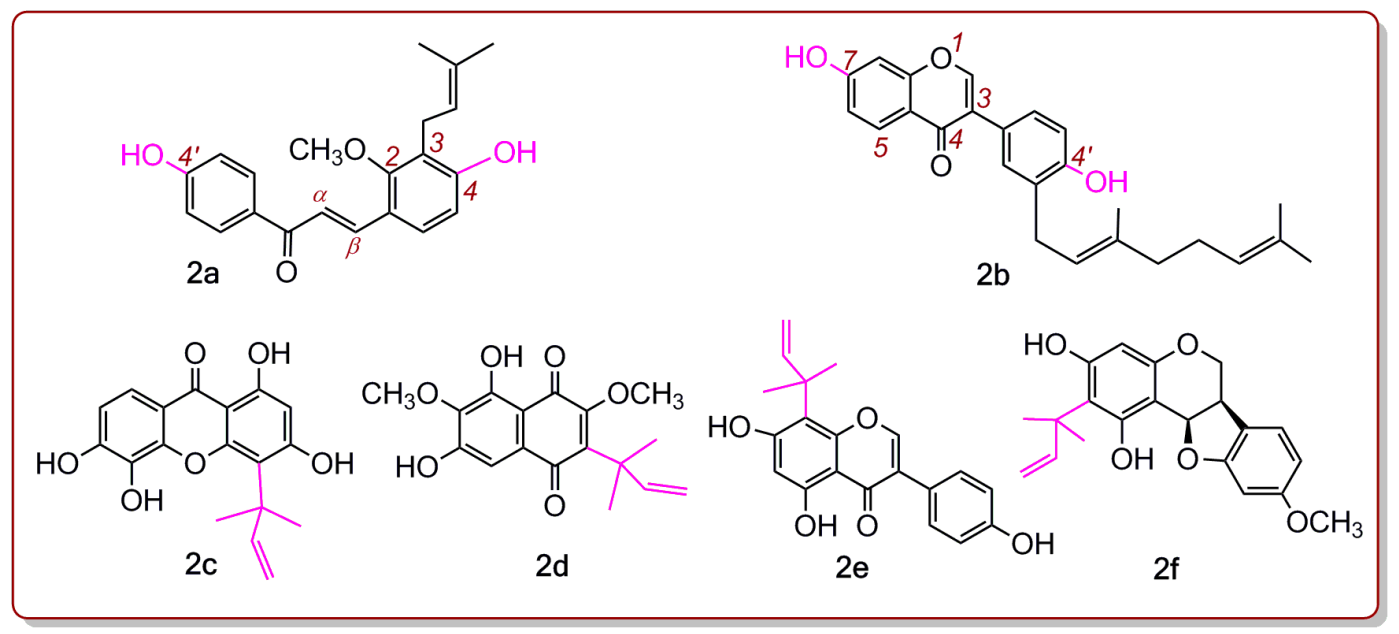

Figure 2. Structures of licochalcone C (2a), corylifol A (2b), isocudraniazanthone A (2c), 6,8-dihydroxy-2,7-dimethoxy-3-(1,1-dimethylprop-2-enyl)-1,4-naphthoquinone (2d), 5,7,4'-trihydroxy-8(1,1-dimethylprop-2-enyl) isoflavone (2e), and glycyuralin B (2f). 
As illustrated Figure 1, licochalcone A is an echinatin derivative with a 1,1-dimethyl-2-propenyl substituent (also called $\alpha, \alpha$-dimethyl- $\beta$-propenyl). If there is an antioxidant activity difference between echinatin and licochalcone $\mathrm{A}$, then it can be attributed to the existence of the 1,1-dimethyl-2-propenyl substituent. As such, parallel studies of echinatin and licochalcone A can well determine whether and how the 1,1-dimethyl-2-propenyl groups affect antioxidant chalcones, and even phytophenols. In fact, 1,1-dimethyl-2-propenyl substituents are widely distributed in phenolics (Supplementary File 2), including xanthones (e.g., isocudraniazanthone A (2c, Figure 2) [13]), naphthoquinones (e.g., 6,8-dihydroxy-2,7-dimethoxy-3-(1,1-dimethylprop-2-enyl)-1,4-naphthoquinone (2d, Figure 2) [14]), isoflavones (e.g., 5,7,4'-trihydroxy-8-(1,1-dimethylprop-2-enyl) isoflavone (2e, Figure 2) [15]), and isoflavanes (e.g., glycyuralin B (2f, Figure 2) [1]). Undoubtedly, the present study will also help us to determine whether the 1,1-dimethyl-2-propenyl substituent affects the antioxidant potentials of these phenolics.

For these purposes, a set of measurements was designed as experiments for determining the antioxidant activity in this study. These antioxidant activity measurements were cupric-ion $\left(\mathrm{Cu}^{2+}\right)$-reduction $(\mathrm{pH} 7.4)$, ferric-ion $\left(\mathrm{Fe}^{3+}\right)$-reduction $(\mathrm{pH} 3.6)$, 2-phenyl-4,4,5,5-tetramethylimidazoline-1-oxyl 3-oxide radical (PTIO•)-scavenging ( $\mathrm{pH}$ 7.4), and 1,1-diphenyl-2-picrylhydrazyl radical (DPPH•)-scavenging colorimetric measurements. The reaction products from the DPPH•-scavenging measurements were further investigated using ultra-performance liquid chromatography coupled with electrospray ionization quadrupole time-of-flight tandem mass spectrometry (UPLC-ESI-Q-TOF-MS/MS). Because the mechanisms of these antioxidant activity measurements are distinctive and complementary, it is believed that this study will bring reliable experimental results.

\section{Results and Discussion}

The antioxidant mechanisms of phenolics are suggested to involve electron transfer (ET) [16], proton transfer (PT) [17], proton-coupled electron transfer (PCET) [18], concerted proton electron transfer (CPET) [19], ET-PT (or sequential electron proton transfer, SEPT) [20], PT-ET (or sequential proton loss electron transfer, SPLET) [21], or hydrogen atom transfer (HAT) pathways [22-25]. These antioxidant mechanisms are seemingly different from each other; however, all of these are essentially made up of two elemental reactions, i.e., an ET reaction and a PT reaction. The difference between them lies only in the sequence and collaboration.

To test the possibility of ET, echinatin and licochalcone A were individually examined using a $\mathrm{Fe}^{3+}$-reduction measurement at $\mathrm{pH}$ 3.6. To determine whether a $\mathrm{pH}$ of 3.6 suppressed PT (i.e., phenolic-OH ionization), we calculated the molar concentration of deprotonated echinatin (c, Figure 3 and Equation (1)) [13].

$$
\mathrm{Ka}=\frac{\left[\mathrm{H}^{+}\right] \cdot c}{([\text { Echinatin }]-c)}
$$

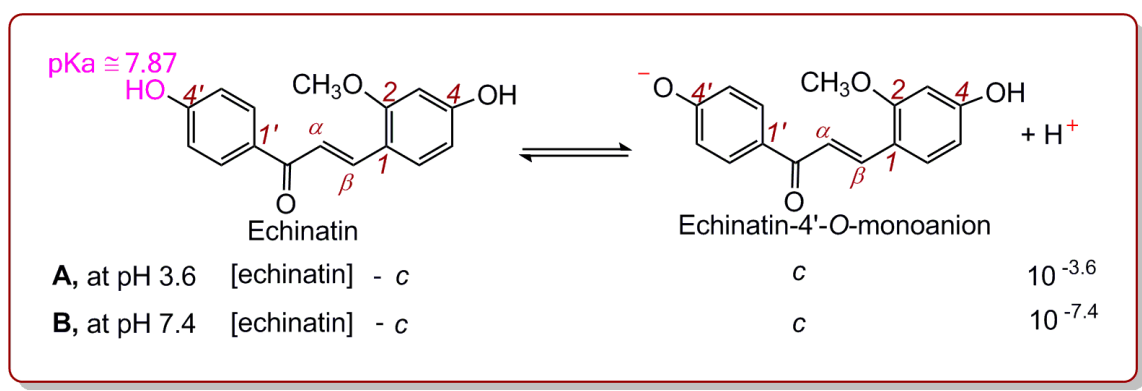

Figure 3. Ionization equilibrium of the $4^{\prime}-\mathrm{OH}$ group in echinatin at $\mathrm{pH} 3.6(\mathrm{~A})$ and 7.4 (B). 
As shown in Figure 3, echinatin has two potential $\mathrm{H}^{+}$ionization sites, i.e., the $4^{\prime}-\mathrm{OH}$ and $4-\mathrm{OH}$ groups. If $4^{\prime}-\mathrm{OH}$ ionization occurs, echinatin-4'-O-monoanion, one form of deprotonated echinatin, is produced (Figure 3A). However, the $\mathrm{pKa}$ values for the $4^{\prime}-\mathrm{OH}$ and $4-\mathrm{OH}$ groups of echinatin are not available; thus, we consulted the pKa value of its analogue, hydroxyacetophenone, which is 7.87 [26]. At $\mathrm{pH}$ 3.6, the ionization equilibrium constant equation was as follows (Equation (2)):

$$
10^{-7.87}=\frac{\left[10^{-3.6}\right] \cdot c}{([\text { Echinatin }]-c)}
$$

In our experiments, the tested concentrations of echinatin varied from 70.1 to $370.4 \mu \mathrm{M}$ (Supplementary File 3). When the concentration of echinatin (i.e., [echinatin]) was 70.1 and $370.4 \mu \mathrm{M}$, the echinatin-4'-O-monoanion concentrations (c) were calculated to be $3.76 \times 10^{-6}$ and $1.99 \times 10^{-5} \mu \mathrm{M}$, respectively, using Equation (2). In these cases, the deprotonation percentages were 0.0053\% $\left(3.76 \times 10^{-6} / 70.1\right.$ or $\left.1.99 \times 10^{-5} / 370.4\right)$.

However, if 4-OH ionization occurs, echinatin-4-O-monoanion, another form of deprotonated echinatin, is produced (Figure $4 \mathrm{~A}$ ). It is roughly equivalent to curcumin, which has been indicated to have a $\mathrm{pKa}$ of 8.38 [27]. Correspondingly, the ionization equilibrium constant equation can be expressed as Equation (3). When [echinatin] was 70.1 and $370.4 \mu \mathrm{M}$, the echinatin-4-O-monoanion concentrations $(c)$ were calculated to be $1.16 \times 10^{-6}$ and $6.15 \times 10^{-6} \mu \mathrm{M}$, respectively, using Equation (3). Hence, its deprotonation percentages were $0.0016 \%\left(1.16 \times 10^{-6} / 70.1\right.$ or $\left.6.15 \times 10^{-6} / 370.4\right)$.

$$
10^{-8.38}=\frac{\left[10^{-3.6}\right] \cdot c}{([\text { Echinatin }]-c)}
$$

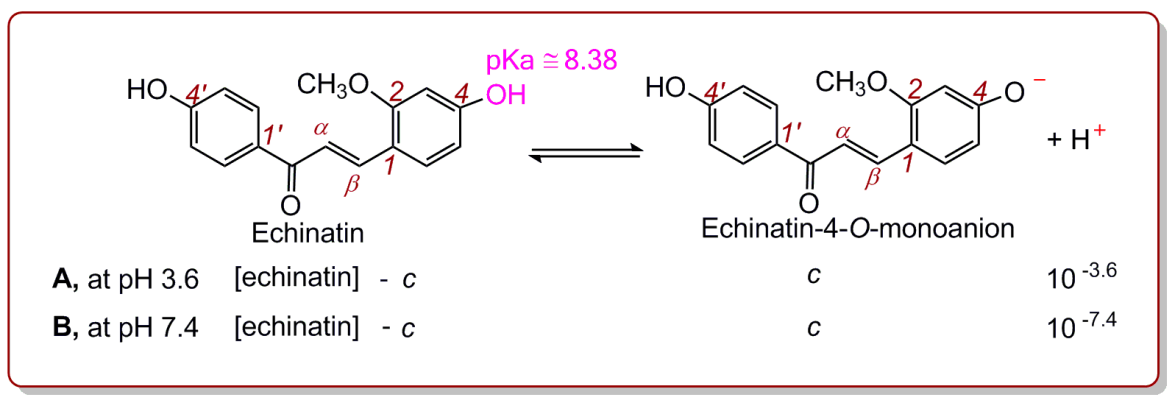

Figure 4. Ionization equilibrium of the 4-OH group in echinatin at $\mathrm{pH} 3.6$ (A) and 7.4 (B).

The values of $0.0053 \%$ and $0.0016 \%$ suggested that both the $4^{\prime}-\mathrm{OH}$ and $4-\mathrm{OH}$ groups in echinatin, respectively, are not deprotonated in a pH 3.6 buffer. Regardless, the two pKa values (7.86 and 8.38) were somewhat inaccurate, and relevant calculations for licochalcone A have not been performed; however, the conclusion that a $\mathrm{pH}$ of 3.6 effectively suppressed $\mathrm{H}^{+}$ionization (i.e., deprotonation and PT) is generally reasonable. This is also in agreement with the previous literature [28]. On the other hand, our experimental data showed that echinatin and licochalcone A efficiently reduced $\mathrm{Fe}^{3+}$ to $\mathrm{Fe}^{2+}$ at pH 3.6 (Supplementary File 3 and Table 1). This means that both echinatin and licochalcone A have ET potentials under conditions where $\mathrm{H}^{+}$ionization is suppressed. The ET potentials of echinatin and licochalcone A can explain why chalcones can alter the redox status of Jurkat T cells [29]. 
Table 1. $\mathrm{IC}_{50}$ values $(\mu \mathrm{M})$ of echinatin and licochalcone A from the four sets of antioxidant colorimetric measurements.

\begin{tabular}{cccc}
\hline Measurement & Echinatin & Licochalcone A & Trolox \\
\hline $\mathrm{Fe}^{3+}$-reduction & $338.0 \pm 8.6^{\mathrm{c}}$ & $133.2 \pm 0.9^{\mathrm{b}}$ & $87.5 \pm 3.4^{\mathrm{a}}$ \\
$\mathrm{Cu}^{2+}$-reduction & $228.1 \pm 10.6^{\mathrm{c}}$ & $129.1 \pm 2.1^{\mathrm{b}}$ & $67.5 \pm 0.9^{\mathrm{a}}$ \\
$\mathrm{PTIO \bullet -scavenging}$ & $1276.5 \pm 149.9^{\mathrm{c}}$ & $617.4 \pm 22.9^{\mathrm{b}}$ & $270.9 \pm 10.8^{\mathrm{a}}$ \\
DPPH•-scavenging & $394.2 \pm 67.5^{\mathrm{c}}$ & $102.3 \pm 3.6^{\mathrm{b}}$ & $47.8 \pm 2.6^{\mathrm{a}}$ \\
\hline
\end{tabular}

The $\mathrm{IC}_{50}$ value was defined as the final concentration of $50 \%$ radical inhibition or relative reduction power, calculated using linear regression analysis, and expressed as the mean \pm standard deviation (SD) $(n=3)$. The linear regression was analyzed using the Origin Professional software (2017 version). $\mathrm{IC}_{50}$ values in the same row with different superscripts $\left({ }^{\mathrm{a}}, \mathrm{b}\right.$, or $\left.^{\mathrm{c}}\right)$ were significantly different $(p<0.05)$. Trolox was the positive control. The dose-response curves are shown in Supplementary File 3.

Similarly, the deprotonation percentages of echinatin at the physiological $\mathrm{pH}$ of 7.4 can also be calculated by using the relevant formula. The calculation revealed that, at $\mathrm{pH} 7.4$, the $4^{\prime}-\mathrm{OH}$ and 4-OH groups in echinatin showed $25.3 \%$ and $9.5 \%$ deprotonation, respectively. This means that PT for echinatin and licochalcone $\mathrm{A}$ is facilitated at $\mathrm{pH}$ 7.4. For further investigation, echinatin and licochalcone A were evaluated using the $\mathrm{Cu}^{2+}$-reduction method at $\mathrm{pH}$ 7.4. The results showed that the $\mathrm{Cu}^{2+}$-reduction percentages for both echinatin and licochalcone $\mathrm{A}$ increased in a dose-dependent manner (Supplementary File 3). In fact, the $\mathrm{Cu}^{2+}$-reduction measurements have been reported to involve ET and PT. However, the destination of the PT is the solution rather than the $\mathrm{Cu}^{+}$complex $[30,31]$.

In order to assess whether they can transfer $\mathrm{H}^{+}$to a free radical, both echinatin and licochalcone A were examined using PITO•-scavenging colorimetric measurement, a method that was newly established by our team [17]. During PITO• scavenging, an electron and a proton were transferred to PITO• to form PITO-H [32]. The observations that echinatin and licochalcone A effectively scavenged PITO• radicals (Supplementary File 3) implied that they both have ET and PT potential in aqueous solution. This can partially explain the fact that aqueous extracts of Gancao as an antioxidant show a protective effects in a renal hypoxia (ischemia) reoxygenation (reperfusion) model [33].

The reason that both echinatin and licochalcone A exhibited PT potential may be that the $\mathrm{Cu}^{2+}$-reduction and PITO•-scavenging experiments were conducted in aqueous solutions. Water, which is strongly polar (dielectric constant $\varepsilon=78.36 \mathrm{~F} / \mathrm{m}$ ), can force phenolic $-\mathrm{OH}$ groups to ionize (deprotonate) via solvation. In contrast, organic molecules are weakly polar (e.g., methanol $\varepsilon=32.7 \mathrm{~F} / \mathrm{m}$ ) and can force phenolic $-\mathrm{OH}$ groups to ionize slightly via solvation. Thus, in methanol solution, phenols may transfer hydrogen mainly through a hydrogen atom $(\mathrm{H} \bullet)$ pathway rather than a hydrogen ion $\left(\mathrm{H}^{+}\right)$pathway. This is known as an HAT mechanism [34]. The fact that a hydrogen atom carries an electron makes HAT a redox-based antioxidant mechanism. Typically, DPPH•-scavenging determination in alcoholic solutions can be used to examine the HAT of a phenolic antioxidant [35-37].

Now, given that a HAT reaction takes place for echinatin (and licochalcone A), there are only two reaction sites, i.e., 4-OH and $4^{\prime}-\mathrm{OH}$. The HAT reaction of the 4-OH group produces an echinatin-4-O• radical, which has six resonance structures (I-VI) (Figure 5); meanwhile, the HAT reaction of the $4^{\prime}-\mathrm{OH}$ group produces an echinatin- $4^{\prime}-\mathrm{O} \bullet$ radical, which has only five resonance structures (VII-XI). Thus, the echinatin-4-O• radical is more stable, which implies that the 4-OH group has more HAT potential than the $4{ }^{\prime}-\mathrm{OH}$ group. After an HAT reaction at the 4-OH group, six intermediate radicals (i.e., I-VI) are generated. These radicals may combine with each other via covalent bonding to form radical adduct formation (RAF) products. However, RAF products can be monitored easily using UPLC-ESI-Q-TOF-MS/MS analysis [38]. The main results are shown in Figure 6. 


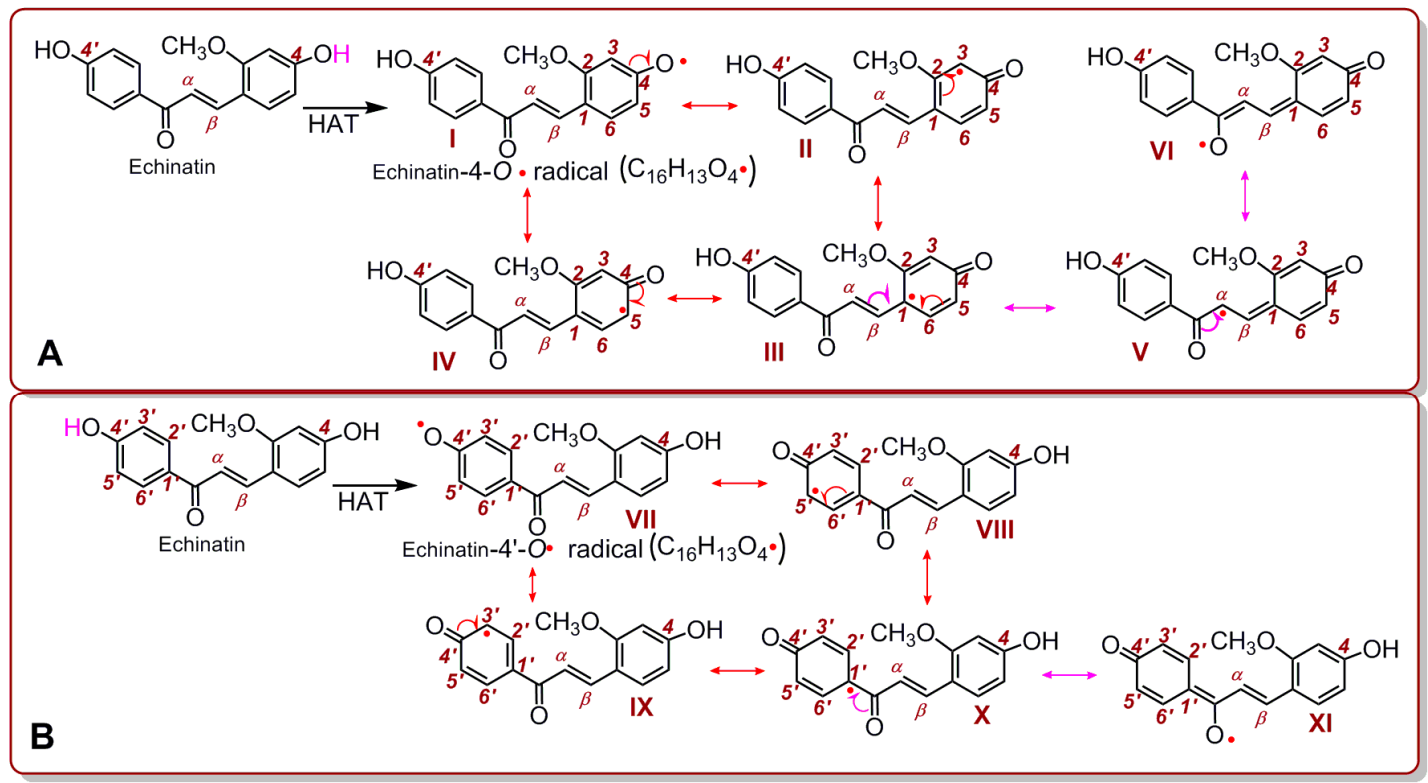

Figure 5. Resonance structures of the echinatin-4-O• radical (A) and the echinatin-4'-O• radical (B).
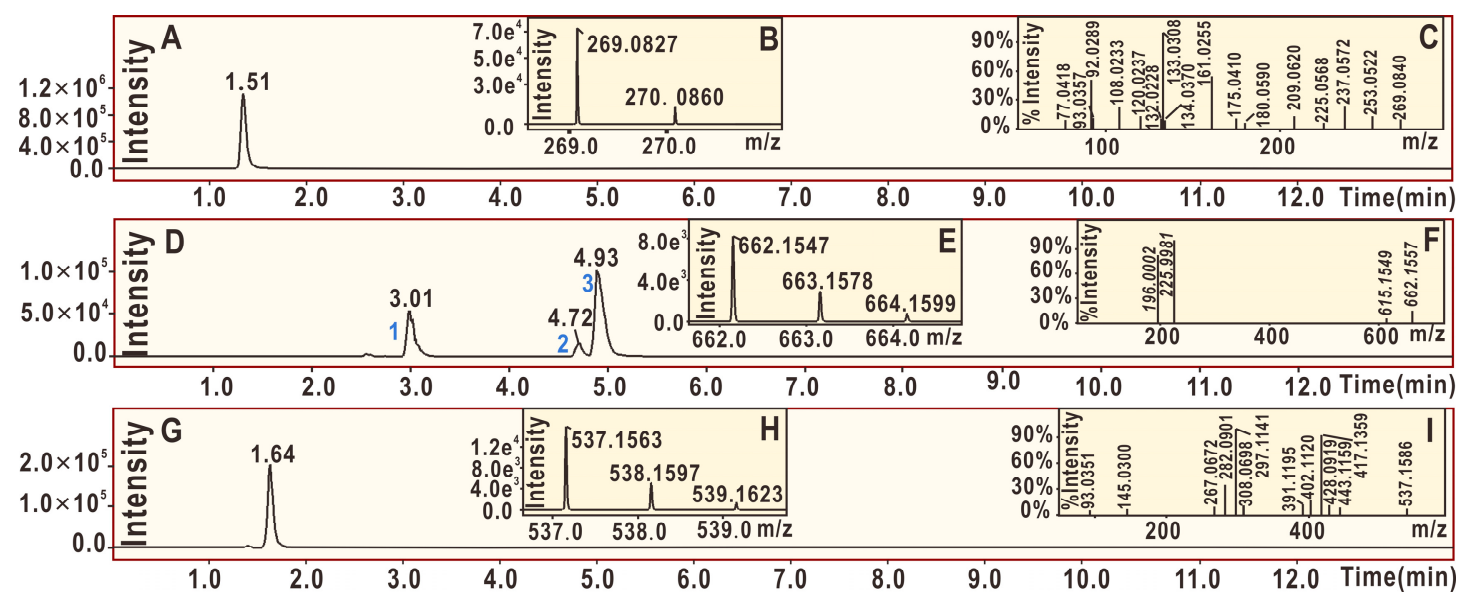

Figure 6. Main results of UPLC-ESI-Q-TOF-MS/MS analysis of echinatin: (A) total ion chromatographic diagram of echinatin; (B) primary MS spectrum of echinatin; (C) MS/MS spectrum of echinatin; (D) total ion chromatographic diagram of the RAF products of echinatin and DPPH $\bullet$ radical extracted by $\left[\mathrm{C}_{34} \mathrm{H}_{25} \mathrm{~N}_{5} \mathrm{O}_{10}-\mathrm{H}\right]^{-}$; (E) primary MS spectra of echinatin-DPPH adducts (from peaks 1 to 3 in (D)); (F) MS/MS spectra of echinatin-DPPH adducts from peak 3 in (D); (G) total ion chromatographic diagram of the possible dimeric products of echinatin extracted by $\left[\mathrm{C}_{32} \mathrm{H}_{26} \mathrm{O}_{8}-\mathrm{H}\right]^{-} ;(\mathbf{H})$ primary MS spectrum of the echinatin-echinatin dimer; and (I) MS/MS spectrum of the echinatin-echinatin dimer.

As shown in Figure 6D, from the product of the reaction between echinatin and the DPPH $\bullet$ radical, at least three chromatographic peaks (1-3) were found through UPLC-ESI-Q-TOF-MS/MS analysis. Subsequent examination of the MS spectra suggested that three chromatographic peaks could each present an $m / z$ value of 662 (Figure $6 \mathrm{D}, \mathrm{E}$ ). This value, however, was exactly two units less than the sum of the molecular weights of echinatin (M.W. 270) and the DPPH• radical (M.W. 394). Thus, we initially assumed that the four peaks corresponded to echinatin-DPPH adducts. Out of the three peaks, peak 3 could be broken down further to produce an MS/MS spectrum that showed four main fragments $(\mathrm{m} / \mathrm{z}$ $662,615,226$, and 196, Figure 6F). In light of previous evidence [39], the echinatin-DPPH adduct was assumed to be 7a (Figure 7), and its MS spectrum has been fully elucidated and is shown in Figure 8A. Despite these fragments (Figure 6F), other possible echinatin-DPPH adduct structures can be deduced; however, it is definitive that echinatin and $\mathrm{DPPH}^{\bullet}$ radical generated $\mathrm{RAF}$ products. 


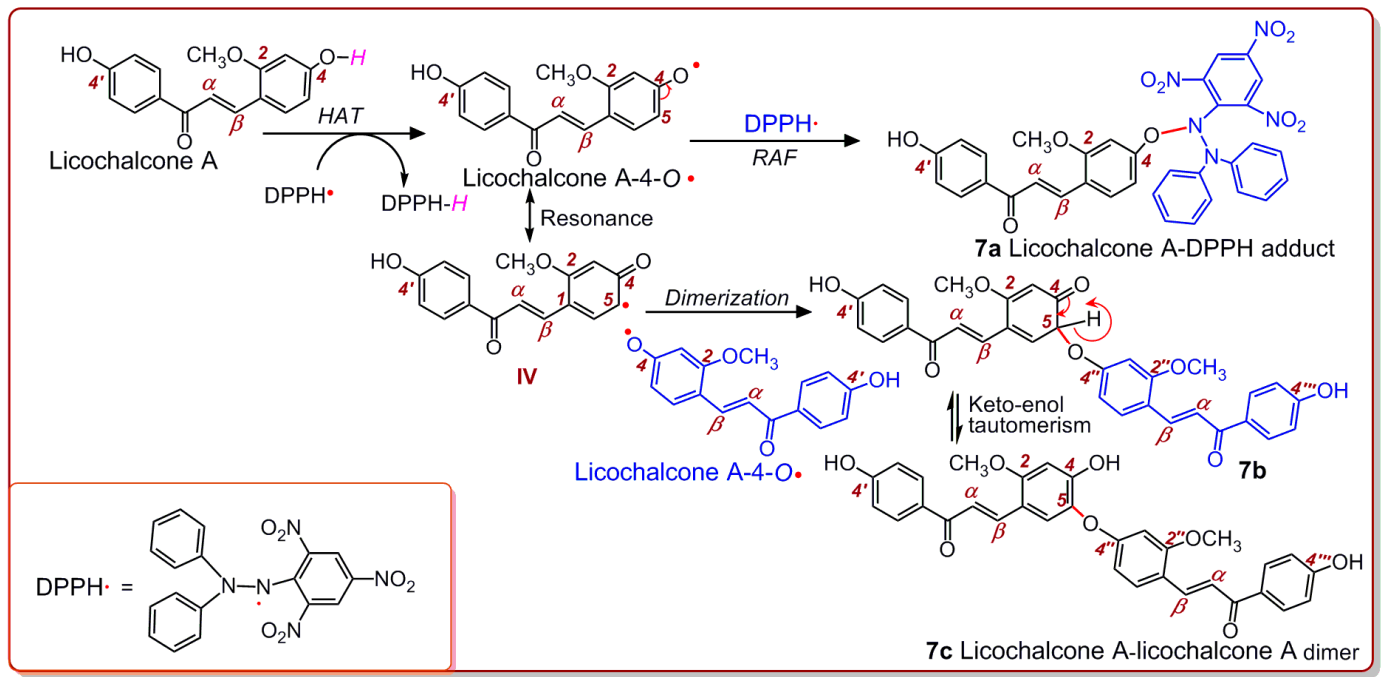

Figure 7. Proposed RAF reactions of echinatin when mixed with the DPPH• radical.

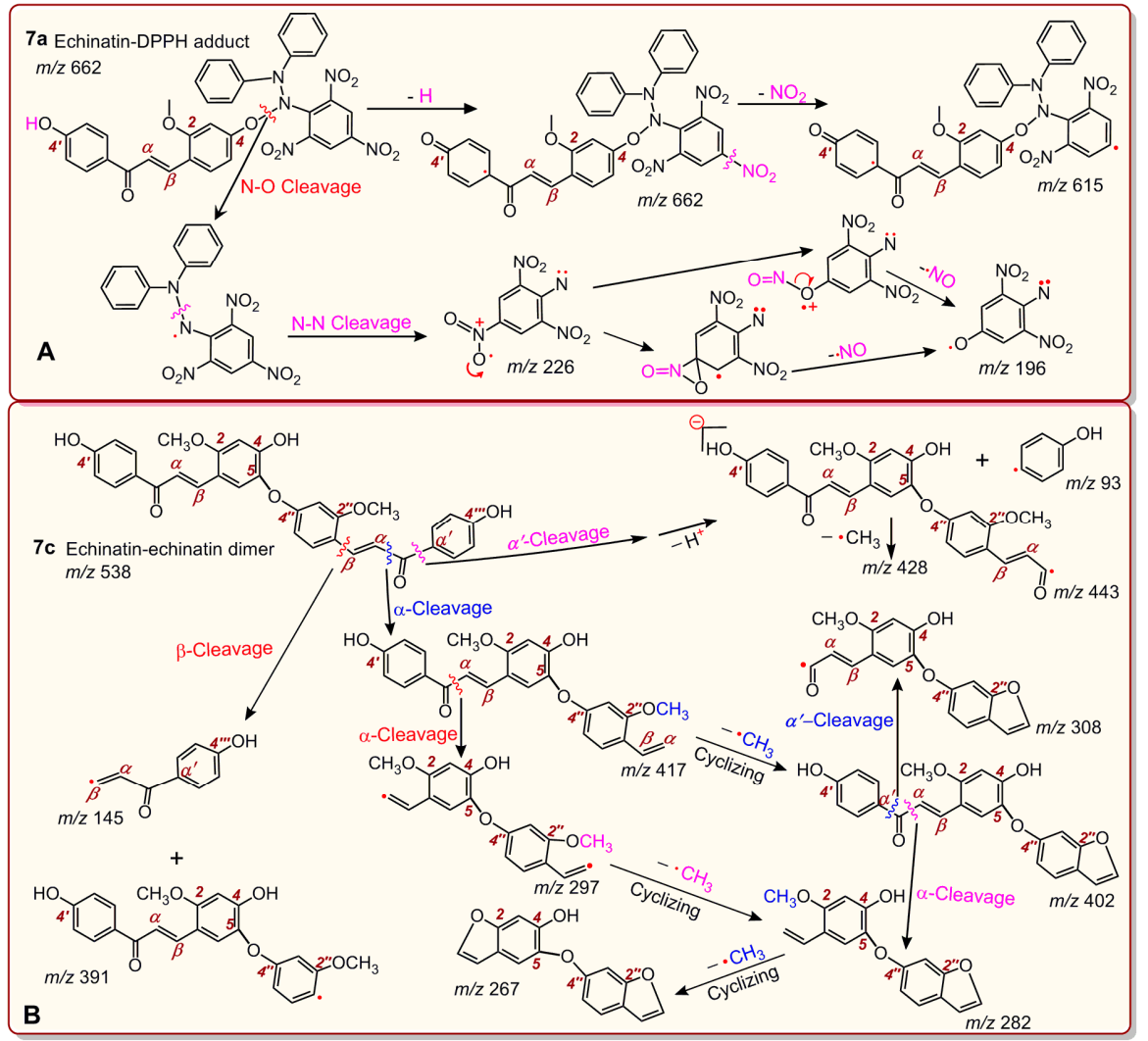

Figure 8. Full MS elucidation of the echinatin-DPPH adduct (A) and the echinatin-echinatin dimer (B). The MS spectra were obtained in the negative ion mode and the charge imposed by the MS field was not marked. Other reasonable cleavages should not be excluded in the MS elucidation.

In addition to echinatin-DPPH adducts, the echinatin-echinatin dimer may also be formed during the reaction of echinatin with the DPPH• radical. The 4-O of the above echinatin intermediate radical (I, Figure 5) links to the 5-C of structure IV, producing an echinatin-echinatin dimer [24], and it is re-numbered as $4 "-\mathrm{O}(7 \mathbf{b}$, Figure 7$)$. Then, $7 \mathbf{b}$ undergoes keto-enol tautomerization to produce the stable echinatin-echinatin dimer $7 \mathrm{c}$ (Figure 7). The structure of $7 \mathrm{c}$ can be further confirmed through full MS spectrum elucidation (Figure 8B). 
The reaction of echinatin with the DPPH• radical yields two types of RAF products (i.e., the echinatin-DPPH adduct and the echinatin-echinatin dimer). The discovery of the two types of RAF products suggested that echinatin scavenges DPPH• radicals through HAT. This is because RAF depends on the covalent bonding between two (intermediate) radicals [40]; however, the production of intermediate radicals depends on the HAT reaction.

Similarly, licochalcone A also generated three peaks for licochalcone A-DPPH adducts (Figure 9D) and two peaks for the licochalcone A-licochalcone A dimer (Figure $9 \mathrm{H}$ ) after treatment with the $\mathrm{DPPH} \bullet$ radical. One possible structure of the licochalcone A-DPPH adducts is 10a, while one possible structure of the licochalcone A-licochalcone A dimers is 10b (Figure 10). The structures of both 10a and $\mathbf{1 0 b}$ were fully elucidated through their MS spectra, which are shown in Figure 11.
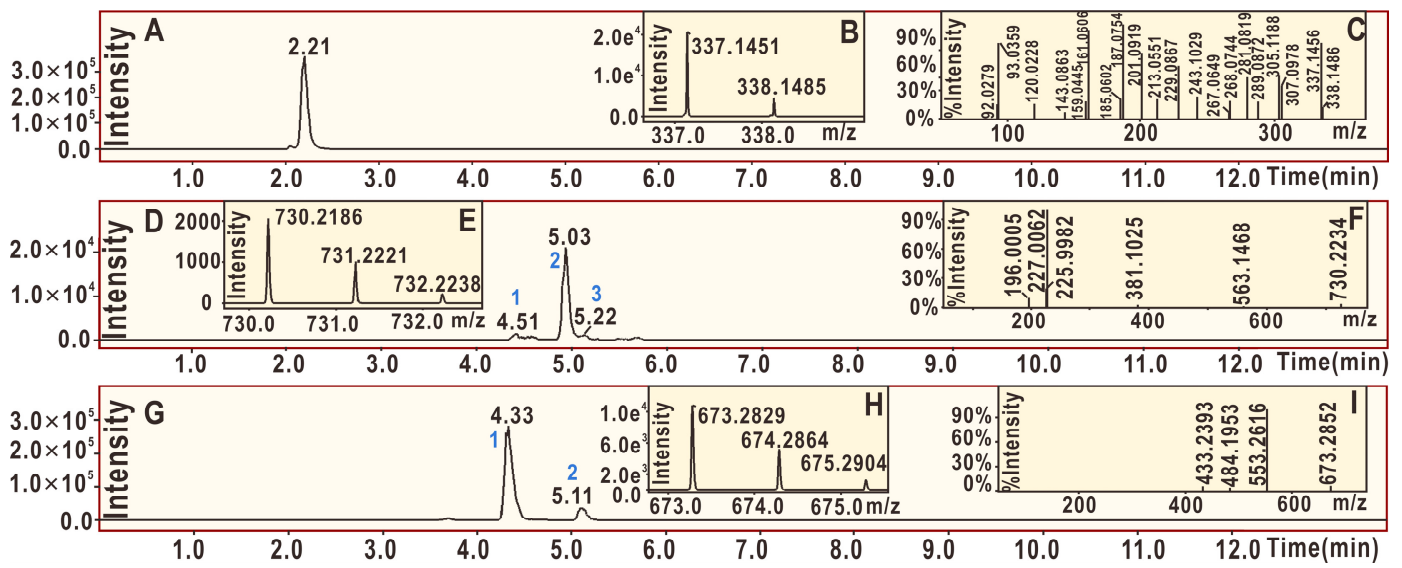

Figure 9. Main results of the UPLC-ESI-Q-TOF-MS/MS analysis of licochalcone A: (A) total ion chromatographic diagram of licochalcone A; (B) primary MS spectrum of licochalcone A; (C) MS/MS spectrum of licochalcone $\mathrm{A}$; (D) total ion chromatographic diagram of the licochalcone A-DPPH adduct extracted by $\left[\mathrm{C}_{39} \mathrm{H}_{33} \mathrm{~N}_{5} \mathrm{O}_{10}-\mathrm{H}\right]^{-}$; (E) primary MS spectrum of the licochalcone A-DPPH adduct; (F) MS/MS spectrum of the licochalcone A-DPPH adduct from peak 2 in (D); (G) total ion chromatographic diagram of the possible dimeric products of licochalcone A extracted by $\left[\mathrm{C}_{42} \mathrm{H}_{42} \mathrm{O}_{8}-\mathrm{H}\right]^{-} ;(\mathbf{H})$ primary MS spectrum of the licochalcone A-licochalcone A dimer; and (I) MS/MS spectrum of the licochalcone A-licochalcone A dimer from peak 1.

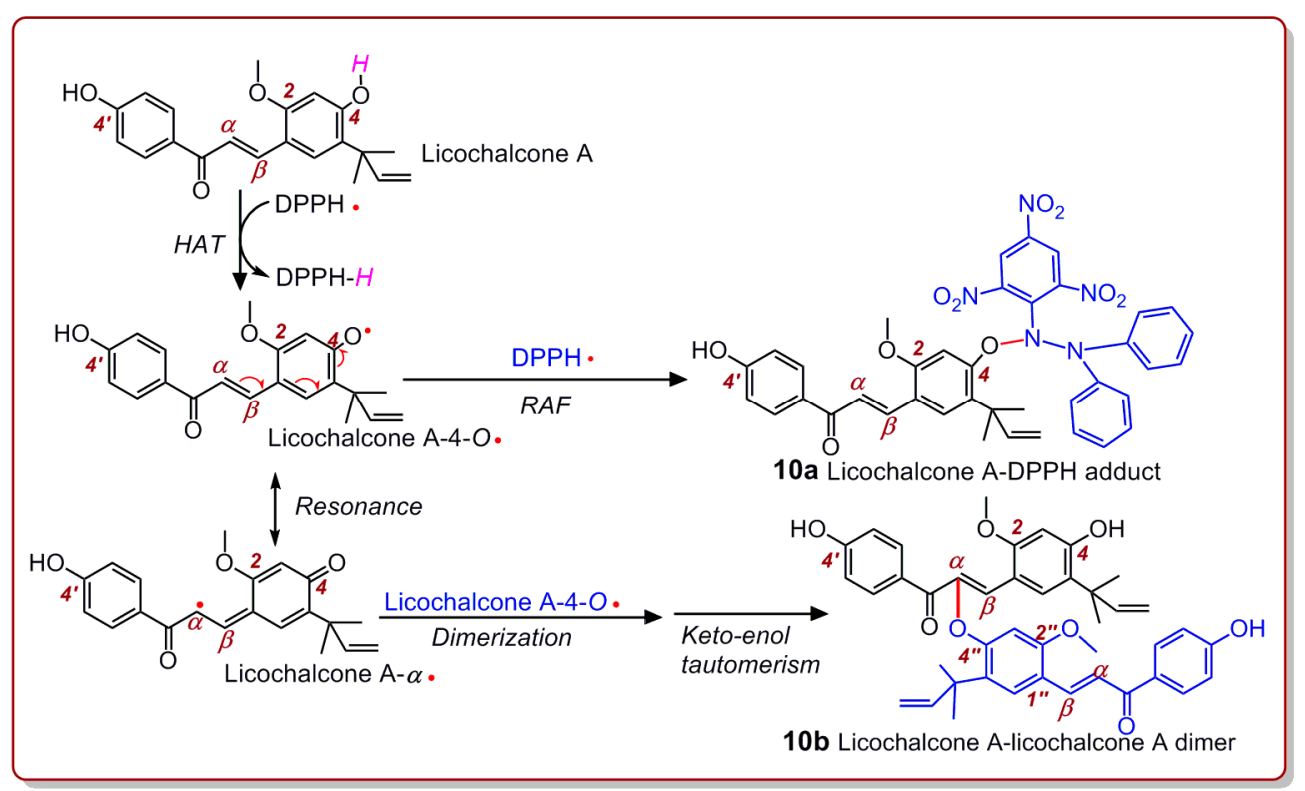

Figure 10. Proposed RAF reactions of licochalcone A when mixed with the DPPH• radical. 


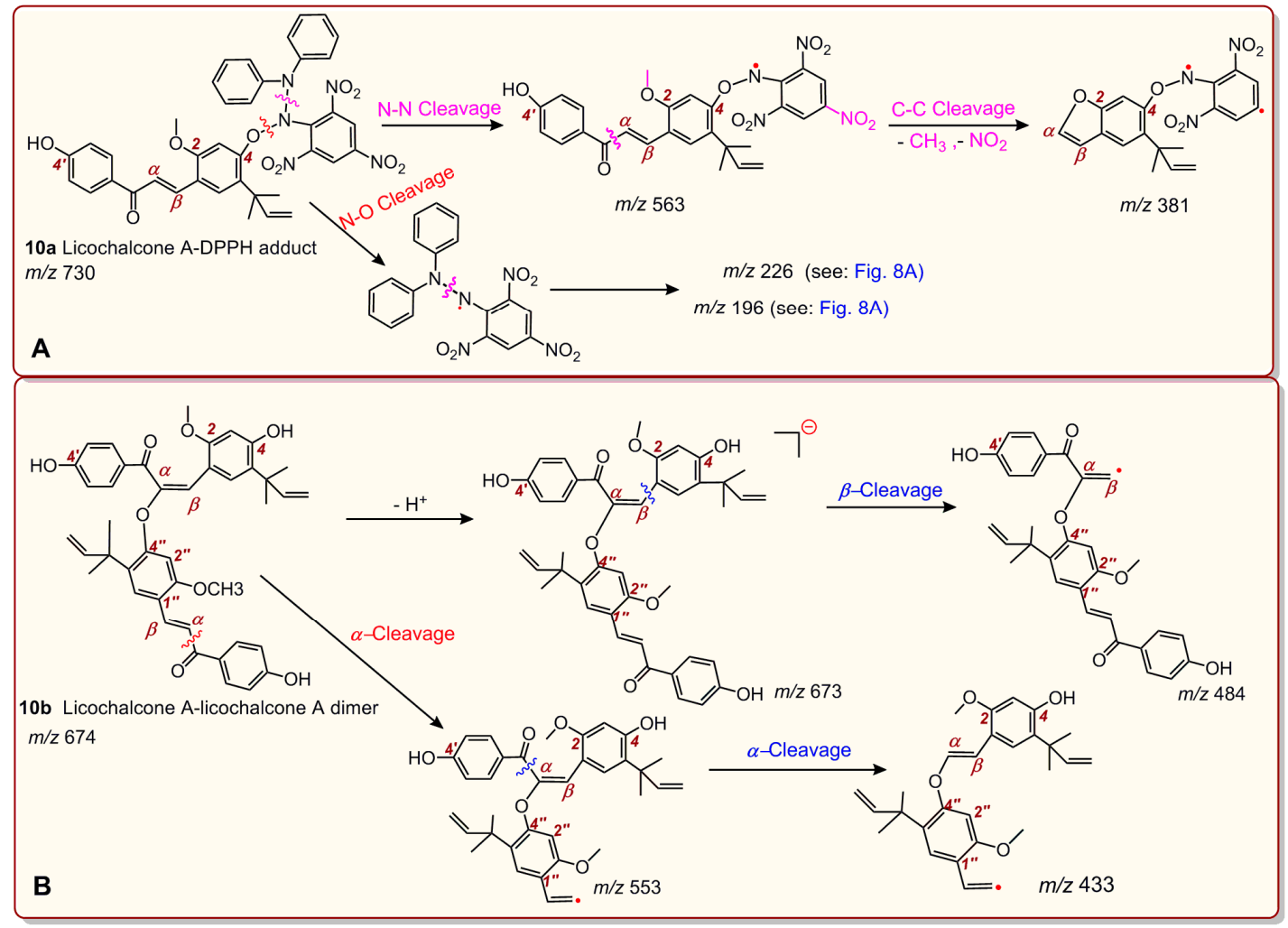

Figure 11. Full MS elucidation of the licochalcone A-DPPH adduct (A) and the licochalcone A-licochalcone A dimer (B). The MS spectra were obtained in the negative ion mode, and the charge imposed by the MS field was not marked. Other reasonable cleavages should not be excluded in the MS elucidation.

Now, it is obvious that, in aqueous solution, the antioxidant mechanisms of echinatin and licochalcone A involve ET and PT; however, in organic solutions, HAT (a combined form of ET and PT) may occur preferentially at the $4-\mathrm{OH}$ group and not at the $4{ }^{\prime}-\mathrm{OH}$ group. Through HAT antioxidant mechanisms, both chalcones can produce two types of RAF products (i.e., the chalcone-chalcone dimer and the chalcone-radical adduct).

It should be noted that (1) a higher HAT potential does not mean more PT. As discussed above, it is easier for the $4^{\prime}-\mathrm{OH}$ group to give $\mathrm{H}^{+}$and to initiate a PT reaction, as it has a lower $\mathrm{pK}_{\mathrm{a}}$ value or lower ionization potentials (IPs). However, a mere PT reaction cannot transfer electrons. Thus, mere PT potential is relevant to the acidic rather than the antioxidant potential. Furthermore, (2) as shown in Figure 5A, echinatin may link with the 4-O atom at other carbon atoms (e.g., 1-C, 3-C, and $\alpha-C)$, in addition to the $5-C$ position. These different linkages may result in similar MS spectra, as shown in Figure 7. Similarly, (3) with licochalcone A, other carbon atoms besides $\alpha-C$ (e.g., 1-C and 3-C) can link to the 4-O (Figure 10). However, regardless of the multiple possibilities mentioned in points 2 and 3, it is certainly clear that dimeric echinatin (or licochalcone A) is generated in the $\mathrm{DPPH} \bullet$-scavenging reaction.

Finally, the relative antioxidant activities of echinatin and licochalcone A were quantitatively compared, based on their $\mathrm{IC}_{50}$ values. As shown in Table 1, echinatin always gave higher $\mathrm{IC}_{50}$ values than those of licochalcone A. Such a difference can certainly be attributed to the 1,1-dimethyl-2-propenyl substituent at the 5-position of licochalcone A. Accordingly, the 1,1-dimethyl-2-propenyl substituent was assumed to enhance antioxidant chalcones. This enhancement is possibly derived from its electron-donating inductive effect $(+\mathrm{I})$. Of course, more work is required for identification in the future. 


\section{Materials and Methods}

\subsection{Chemicals}

Echinatin $\left(\mathrm{C}_{16} \mathrm{H}_{14} \mathrm{O}_{4}\right.$, CAS number 34221-41-5, M.W. 270.2, purity 99\%, Supplementary File 4) was obtained from Chengdu Alfa Biotechnology Co., Ltd. (Chengdu, China). Licochalcone A $\left(\mathrm{C}_{21} \mathrm{H}_{22} \mathrm{O}_{4}\right.$, CAS number 58749-22-7, M.W. 338.4, purity 98\%, Supplementary File 5) was obtained from BioBioPha Co., Ltd. (Kunming, China). Pyrogallol, 2,4,6-tripyridyl triazine (TPTZ), 2,9-dimethyl-1,10-phenanthroline (neocuproine), and ( \pm )-6-hydroxyl-2,5,7,8tetramethylchromane-2-carboxylic acid (Trolox) were obtained from Sigma-Aldrich (Shanghai, China). 1,1-Diphenyl-2-picrylhydrazyl radical (DPPH•, $\mathrm{C}_{18} \mathrm{H}_{12} \mathrm{~N}_{5} \mathrm{O}_{6}$ ) was obtained from Aladdin Chemical, Ltd. (Shanghai, China). The 2-phenyl-4,4,5,5-tetramethylimidazoline-1-oxyl 3-oxide radical (PTIO•) was obtained from TCI Chemical Co. (Shanghai, China). Water and acetonitrile were high performance liquid chromatography (HPLC) grade. $\mathrm{FeCl}_{3} \cdot 6 \mathrm{H}_{2} \mathrm{O}$ and other reagents were analytical grade and purchased from Guangdong Guanghua Chemical Plants Co., Ltd. (Shantou, China).

\section{2. $\mathrm{Fe}^{3+}-$ Reduction Antioxidant Colorimetric Measurement}

The $\mathrm{Fe}^{3+}$-reduction antioxidant colorimetric measurement used in this study was adapted from the method reported by Benzie and Strain [28]. This measurement can be used to give an indication of the reducing ability of a material or mixture. The measurement was performed in a buffer with a $\mathrm{pH}$ of 3.6. Briefly, in a ratio of 1:1:10, the determining reagent was freshly prepared by mixing together $10 \mathrm{mM}$ TPTZ and $20 \mathrm{mM} \mathrm{FeCl}_{3}$ in $0.25 \mathrm{M}$ acetic acid-sodium aqueous buffer solution (pH 3.6). The test sample $(x=0-10 \mu \mathrm{L}, 0.5 \mathrm{mg} / \mathrm{mL})$ was added to $(20-x) \mu \mathrm{L}$ of methanol, followed by $80 \mu \mathrm{L}$ of the determining reagent. The absorbance at $593 \mathrm{~nm}$ was recorded after $3 \mathrm{~h}$ of incubation at $40^{\circ} \mathrm{C}$ against a blank consisting of an acetate buffer. The relative reducing power of the sample to the maximum absorbance was calculated using the following formula:

$$
\text { Relative reducing power } \%=\frac{A-A_{\min }}{A_{\max }-A_{\min }} \times 100 \%
$$

where $A_{\max }$ is the maximum absorbance, $A_{\min }$ is the minimum absorbance, and $A$ is the absorbance of the sample.

\section{3. $\mathrm{Cu}^{2+}-$ Reduction Antioxidant Spectrophotometric Measurement}

The $\mathrm{Cu}^{2+}$-reduction measurement was performed based on the method proposed by Apak et al. [30], with the small modifications proposed by Tian [41]. In a 96-well plate, $12 \mu \mathrm{L}$ of an aqueous $\mathrm{CuSO}_{4}$ solution $(0.01 \mathrm{M})$ and $12 \mu \mathrm{L}$ of a methanol neocuproine solution $\left(7.5 \times 10^{-3} \mathrm{M}\right)$ were added, and they were mixed with samples of different concentrations $(0-50 \mu \mathrm{g} / \mathrm{mL})$. The total volume was then adjusted to $100 \mu \mathrm{L}$ with an ammonium acetate buffer solution $(0.1 \mathrm{M})$, and the solutions were mixed again to homogenize them. Each mixture was incubated at room temperature for $30 \mathrm{~min}$, and the absorbance was measured at $450 \mathrm{~nm}$ on a microplate reader (Multiskan FC, Thermo Scientific, Shanghai, China). The relative reducing power of the sample was calculated using the following formula:

$$
\text { Relative reducing power } \%=\frac{A-A_{\min }}{A_{\max }-A_{\min }} \times 100 \%
$$

where $A$ is the absorbance of the sample at $450 \mathrm{~nm}, A_{\max }$ is the maximum absorbance at $450 \mathrm{~nm}$, and $A_{\min }$ is the minimum absorbance at $450 \mathrm{~nm}$.

\subsection{PTIO•-Scavenging Colorimetric Measurement}

The PTIO•-scavenging colorimetric measurement was conducted in accordance with our method [17]. In brief, the test sample solution $(x=0-10 \mu \mathrm{L}, 1 \mathrm{mg} / \mathrm{mL})$ was added to $(20-\mathrm{x})$ 
$\mu \mathrm{L}$ of methanol, followed by $80 \mu \mathrm{L}$ of an aqueous PTIO• solution. The mixture was kept at $40{ }^{\circ} \mathrm{C}$ for $2 \mathrm{~h}$, and then the absorbance was measured at $560 \mathrm{~nm}$ using a microplate reader (Multiskan FC, Thermo Scientific, Shanghai, China). The PTIO• inhibition percentage was calculated as follows:

$$
\text { Inhibition } \%=\frac{\mathrm{A}_{0}-\mathrm{A}}{\mathrm{A}_{0}} \times 100 \%
$$

where $A_{0}$ is the absorbance of the control without the sample, and $A$ is the absorbance of the reaction mixture with the sample.

\subsection{DPPH•-Scavenging Colorimetric Measurement}

The DPPH• radical scavenging activity was determined as follows [42]. $80 \mu \mathrm{L}$ of DPPH• solution $(0.1 \mathrm{mM})$ was added to a $96-$ well plate and mixed with samples of different concentrations $(0-50 \mu \mathrm{g} / \mathrm{mL})$. The total volume was then adjusted to $100 \mu \mathrm{L}$ with methanol. The mixture was kept in the dark at room temperature for $30 \mathrm{~min}$, and then the absorbance was measured at $519 \mathrm{~nm}$ on a microplate reader (Multiskan FC, Thermo Scientific, Shanghai, China). The DPPH• inhibition percentages of the samples were calculated by using the formula in Section 3.4.

\subsection{UPLC-ESI-Q-TOF-MS/MS Analysis of DPPH• Reaction Products with Echinatin and Licochalcone A}

In the echinatin experiment, the reaction product was prepared using the method from our previous study [20]. In brief, a methanol solution of echinatin was mixed with a methanol-DPPH• solution at a molar ratio of 1:2, and the resulting mixture was incubated for $10 \mathrm{~h}$ at room temperature. The product was then filtered through a $0.22 \mu \mathrm{m}$ filter for UPLC-ESI-Q-TOF-MS/MS analysis.

The UPLC-ESI-Q-TOF-MS/MS analysis was based on the method described in our previous report [43]. The analysis system was equipped with a $C_{18}$ column $(2.0 \mathrm{~mm}$ i.d. $\times 100 \mathrm{~mm}, 2.2 \mu \mathrm{m}$, Shimadzu Co., Kyoto, Japan). A mobile phase was used for the elution of the system, and consisted of a mixture of acetonitrile (phase A) and $0.1 \%$ formic acid water (phase B). The column was eluted at a flow rate of $0.2 \mathrm{~mL} / \mathrm{min}$ with the following gradient elution program: $0-2 \mathrm{~min}$, maintained at $30 \%$ B; 2-10 $\mathrm{min}, 30-0 \% \mathrm{~B} ; 10-12 \mathrm{~min}, 0-30 \% \mathrm{~B}$. The sample injection volume was $1 \mu \mathrm{L}$ for the separation of the different components. Q-TOF-MS/MS analysis was performed on a TripleTOF $5600^{+}$mass spectrometer (AB SCIEX, Framingham, MA, USA) equipped with an ESI source, which was operated in the negative ionization mode. The scan range was 100-2000 Da. The system was operated with the following parameters: ion spray voltage, $-4500 \mathrm{~V}$; ion source heater temperature, $550{ }^{\circ} \mathrm{C}$; curtain gas $\left(\mathrm{CUR}, \mathrm{N}_{2}\right.$ ) pressure, 30 psi; nebulizing gas (GS1, air) pressure, 50 psi; and Tis gas (GS2, air) pressure, 50 psi. The declustering potential (DP) was $-100 \mathrm{~V}$, while the collision energy (CE) was $-40 \mathrm{~V}$ with a collision energy spread (CES) of $20 \mathrm{~V}$. The final RAF products were quantified by extracting the corresponding formula (i.e., $\left[\mathrm{C}_{33} \mathrm{H}_{21} \mathrm{~N}_{5} \mathrm{O}_{11}-\mathrm{H}\right]^{-}$for the echinatin-DPPH adduct, and $\left[\mathrm{C}_{30} \mathrm{H}_{18} \mathrm{O}_{10}-\mathrm{H}\right]^{-}$ for the echinatin-echinatin dimer) from the total ion chromatogram and the corresponding peak.

In the licochalcone $\mathrm{A}$ experiment, the above protocols were repeated using licochalcone $\mathrm{A}$. Correspondingly, the extracted formulas were $\left[\mathrm{C}_{27} \mathrm{H}_{16} \mathrm{~N}_{5} \mathrm{O}_{11}-\mathrm{H}\right]^{-}$for the licochalcone A-DPPH adduct and $\left[\mathrm{C}_{18} \mathrm{H}_{10} \mathrm{O}_{10}-\mathrm{H}\right]^{-}$for the licochalcone $\mathrm{A}$-licochalcone A dimer.

\subsection{Statistical Analysis}

The colorimetric measurement tests were performed in triplicate. The measurement results are shown as the mean $\pm \mathrm{SD}$ in the dose-response curves. The $\mathrm{IC}_{50}$ values were calculated using linear regression analysis based on the dose-response curves, and independent-sample $T$ tests were performed to compare the different groups. A $p$ value of less than 0.05 was considered to be statistically significant. Statistical analyses were performed using the software SPSS for Windows version 17.0 (SPSS Inc., Chicago, IL, USA). All of the linear regression analyses described in this paper were processed using the Origin Professional software (2017 version, OriginLab, Northampton, MA, USA). 


\section{Conclusions}

In conclusion, in aqueous solution, both echinatin and licochalcone A may undergo an electron transfer (ET) and a proton transfer (PT) to cause antioxidant action. However, in an alcoholic solution, both of them may prefer HAT to show antioxidant activity. The HAT active site is the 4-OH group rather than the $4^{\prime}-\mathrm{OH}$ group. Accordingly, both can generate final RAF products, i.e., a chalcone-chalcone dimer and a chalcone-radical adduct. In addition, the 1,1-dimethyl-2-propenyl substituent $(\alpha, \alpha$-dimethyl- $\beta$-propenyl substituent) plays a role in improving the antioxidation reaction in both aqueous and alcoholic solutions.

Supplementary Materials: The following are available online at https:/ /www.mdpi.com/xxx/s1. Supplementary File 1, Phenolics with two phenolic -OHs; Supplementary File 2, Phenolics with a 1,1-dimethyl-2-propenyl substituent; Supplementary File 3, Dose-response curves from antioxidant colorimetric measurements; Supplementary File 4, Certificate of analysis of echinatin; Supplementary File 5, Certificate of analysis of licochalcone A.

Author Contributions: X.L. and D.C. conceived and designed the experiments; M.L. and H.X. performed the experiments; X.O. analyzed the data; X.L. wrote the paper. All authors read and approved the final manuscript.

Funding: This research was funded by the National Nature Science Foundation of China (81573558), Guangdong Science and Technology Project (2017A030312009, 2017A050506043), and Guangdong Provincial Education Office Science and Technology Project (2017KCXTD007).

Conflicts of Interest: The authors declare that they have no competing interests.

\section{Abbreviations}

CPET

$\mathrm{DPPH}$

ET

HAT

PCET

PTIO

RAF

SD

SEPT

SPLET

SPSS

TPTZ

Trolox

UPLC-ESI-Q-TOF-MS/MS concerted proton electron transfer

1,1-diphenyl-2-picrylhydrazyl radical

electron transfer

hydrogen atom transfer

proton-coupled electron transfer

2-phenyl-4,4,5,5-tetramethylimidazoline-1-oxyl 3-oxide

radical adduct formation

standard deviation

sequential electron proton transfer

sequential proton loss electron transfer

Statistical Product and Service Solutions

2,4,6-tripyridyl triazine

( \pm )-6-hydroxyl-2,5,7,8-tetramethylchromane-2-carboxylic acid

ultra-performance liquid chromatography coupled with electrospray

ionization quadrupole time-of-flight tandem mass spectrometry

\section{References}

1. Ji, S.; Li, Z.; Song, W.; Wang, Y.; Liang, W.; Li, K.; Tang, S.; Wang, Q.; Qiao, X.; Zhou, D.; et al. Bioactive Constituents of Glycyrrhiza uralensis (Licorice): Discovery of the Effective Components of a Traditional Herbal Medicine. J. Nat. Prod. 2016, 79, 281-292. [CrossRef] [PubMed]

2. Chen, X.; Liu, Z.; Meng, R.; Shi, C.; Guo, N. Antioxidative and anticancer properties of Licochalcone A from licorice. J. Ethnopharmacol. 2017, 198, 331-337. [CrossRef]

3. Wang, X.X.; Liu, G.Y.; Yang, Y.F.; Wu, X.W.; Xu, W.; Yang, X.W. Intestinal Absorption of Triterpenoids and Flavonoids from Glycyrrhizae radix et rhizoma in the Human Caco-2 Monolayer Cell Model. Molecules 2017, 22, 1627. [CrossRef] [PubMed]

4. $\quad$ Lin, Y.; Kuang, Y.; Li, K.; Wang, S.; Ji, S.; Chen, K.; Song, W.; Qiao, X.; Ye, M. Nrf2 activators from Glycyrrhiza inflata and their hepatoprotective activities against CCl4-induced liver injury in mice. Bioorg. Med. Chem. 2017, 25, 5522-5530. [CrossRef] [PubMed]

5. Fu, Y.; Chen, J.; Li, Y.J.; Zheng, Y.F.; Li, P. Antioxidant and anti-inflammatory activities of six flavonoids separated from licorice. Food Chem. 2013, 141, 1063-1071. [CrossRef] 
6. Funakoshi-Tago, M.; Tanabe, S.; Tago, K.; Itoh, H.; Mashino, T.; Sonoda, Y.; Kasahara, T. Licochalcone A potently inhibits tumor necrosis factor alpha-induced nuclear factor-kappaB activation through the direct inhibition of IkappaB kinase complex activation. Mol. Pharmacol. 2009, 76, 745-753. [CrossRef]

7. Lee, C.W.; Yen, F.L.; Huang, H.W.; Wu, T.H.; Ko, H.H.; Tzeng, W.S.; Lin, C.C. Resveratrol nanoparticle system improves dissolution properties and enhances the hepatoprotective effect of resveratrol through antioxidant and anti-inflammatory pathways. J. Agric. Food Chem. 2012, 60, 4662-4671. [CrossRef]

8. Silva, J.B.D.; Mendes, R.F.; Tomasco, V.; Pinto, N.C.C.; de Oliveira, L.G.; Rodrigues, M.N.; Aragao, D.M.O.; Aguiar, J.A.K.; Alves, M.S.; Castanon, M.; et al. New aspects on the hepatoprotective potential associated with the antioxidant, hypocholesterolemic and anti-inflammatory activities of Vernonia condensata Baker. J. Ethnopharmacol. 2017, 198, 399-406. [CrossRef]

9. Sökmen, M.; Akram, K.M. The antioxidant activity of some curcuminoids and chalcones. Inflammopharmacology 2016, 24, 81-86.

10. Kuete, V.; Noumedem, J.A.; Nana, F. Chemistry and pharmacology of 4-hydroxylonchocarpin: A review. Chin. J. Integr. Med. 2013, 19, 475-480. [CrossRef]

11. Sahu, N.K.; Balbhadra, S.S.; Choudhary, J.; Kohli, D.V. Exploring pharmacological significance of chalcone scaffold: A review. Curr. Med. Chem. 2012, 19, 209-225. [CrossRef] [PubMed]

12. Go, M.L.; Wu, X.; Liu, X.L. Chalcones: An update on cytotoxic and chemoprotective properties. Curr. Med. Chem. 2005, 12, 481-499. [CrossRef] [PubMed]

13. Martinez, A.; Hernandez-Marin, E.; Galano, A. Xanthones as antioxidants: A theoretical study on the thermodynamics and kinetics of the single electron transfer mechanism. Food Funct. 2012, 3, 442-450. [CrossRef] [PubMed]

14. Zhong, Y.J.; Wen, Q.F.; Li, C.Y.; Su, X.H.; Yuan, Z.P.; Li, Y.F. Two New Naphthoquinone Derivatives from Lysionotus pauciflorus. Helv. Chim. Acta 2013, 96, 1750-1756. [CrossRef]

15. Rahman, M.M.; Sarker, S.D.; Byres, M.; Gray, A.I. New salicylic acid and isoflavone derivatives from Flemingia paniculata. J. Nat. Prod. 2004, 67, 402-406. [CrossRef] [PubMed]

16. Xie, H.; Li, X.C.; Ren, Z.X.; Qiu, W.M.; Chen, J.L.; Jiang, Q.; Chen, B.; Chen, D.F. Antioxidant and Cytoprotective Effects of Tibetan Tea and Its Phenolic Components. Molecules 2018, 23, 179. [CrossRef]

17. Li, X.C. 2-Phenyl-4,4,5,5-tetramethylimidazoline-1-oxyl 3-Oxide (PTIO•) Radical Scavenging: A New and Simple Antioxidant Assay In Vitro. J. Agric. Food Chem. 2017, 65, 6288-6297. [CrossRef] [PubMed]

18. Foti, M.C.; Daquino, C.; Mackie, I.D.; DiLabio, G.A.; Ingold, K.U. Reaction of phenols with the 2,2-diphenyl-1-picrylhydrazyl radical. Kinetics and DFT calculations applied to determine ArO-H bond dissociation enthalpies and reaction mechanism. J. Org. Chem. 2008, 73, 9270-9282. [CrossRef]

19. Schrauben, J.N.; Cattaneo, M.; Day, T.C.; Tenderholt, A.L.; Mayer, J.M. Multiple-site concerted proton-electron transfer reactions of hydrogen-bonded phenols are nonadiabatic and well described by semiclassical Marcus theory. J. Am. Chem. Soc. 2012, 134, 16635-16645. [CrossRef]

20. Li, X.C.; Han, L.; Li, Y.R.; Zhang, J.; Chen, J.M.; Lu, W.B.; Zhao, X.J.; Lai, Y.Y.; Chen, D.F.; Wei, G. Protective Effect of Sinapine against Hydroxyl Radical-Induced Damage to Mesenchymal Stem Cells and Possible Mechanisms. Chem. Pharm. Bull. 2016, 64, 319-325. [CrossRef]

21. Li, X.; Xie, Y.; Li, K.; Wu, A.; Xie, H.; Guo, Q.; Xue, P.; Maleshibek, Y.; Zhao, W.; Guo, J.; et al. Antioxidation and Cytoprotection of Acteoside and Its Derivatives: Comparison and Mechanistic Chemistry. Molecules 2018, 23, 498. [CrossRef] [PubMed]

22. Li, X.C.; Jiang, Q.; Wang, T.T.; Liu, J.J.; Chen, D.F. Comparison of the Antioxidant Effects of Quercitrin and Isoquercitrin: Understanding the Role of the 6"-OH Group. Molecules 2016, 21, 1246. [CrossRef] [PubMed]

23. Lopez-Munguia, A.; Hernandez-Romero, Y.; Pedraza-Chaverri, J.; Miranda-Molina, A.; Regla, I.; Martinez, A.; Castillo, E. Phenylpropanoid glycoside analogues: Enzymatic synthesis, antioxidant activity and theoretical study of their free radical scavenger mechanism. PLoS ONE 2011, 6, e20115. [CrossRef]

24. Fourre, I.; Di Meo, F.; Podloucka, P.; Otyepka, M.; Trouillas, P. Dimerization of quercetin, Diels-Alder vs. radical-coupling approach: A joint thermodynamics, kinetics, and topological study. J. Mol. Model. 2016, 22, 190. [CrossRef] [PubMed]

25. Li, X.; Chen, B.; Xie, H.; He, Y.; Zhong, D.; Chen, D. Antioxidant Structure-Activity Relationship Analysis of Five Dihydrochalcones. Molecules 2018, 23, 1162. [CrossRef] [PubMed]

26. Musialik, M.; Kuzmicz, R.; Pawlowski, T.S.; Litwinienko, G. Acidity of hydroxyl groups: An overlooked influence on antiradical properties of flavonoids. J. Org. Chem. 2009, 74, 2699-2709. [CrossRef] 
27. Navas Diaz, A.; Ramos Peinado, M.C. Fluorometric determination of curcumin in yogurt and mustard. J. Agric. Food Chem. 1992, 40, 56-59. [CrossRef]

28. Benzie, I.F.F.; Strain, J.J. The ferric reducing ability of plasma (FRAP) as a measure of "antioxidant power": The FRAP assay. Anal. Biochem. 1996, 239, 70-76. [CrossRef] [PubMed]

29. Rozmer, Z.; Berki, T.; Maasz, G.; Perjesi, P. Different effects of two cyclic chalcone analogues on redox status of Jurkat T cells. Toxicol. Vitro 2014, 28, 1359-1365. [CrossRef]

30. Apak, R.; Guclu, K.; Ozyurek, M.; Bektas Oglu, B.; Bener, M. Cupric ion reducing antioxidant capacity assay for food antioxidants: Vitamins, polyphenolics, and flavonoids in food extracts. Methods Mol. Biol. 2008, 477, 163-193.

31. Gulcin, I. Antioxidant activity of food constituents: An overview. Arch. Toxicol. 2012, 86, 345-391. [CrossRef] [PubMed]

32. Goldstein, S.; Russo, A.; Samuni, A. Reactions of PTIO and carboxy-PTIO with $\bullet N O, \bullet \mathrm{NO}_{2}$, and $\bullet \mathrm{O}_{2}{ }^{-}$. J. Biol. Chem. 2003, 278, 50949-50955. [CrossRef] [PubMed]

33. Yokozawa, T.; Liu, Z.W.; Chen, C.P. Protective effects of Glycyrrhizae radix extract and its compounds in a renal hypoxia (ischemia)-reoxygenation (reperfusion) model. Phytomedicine 2000, 6, 439-445. [CrossRef]

34. Jiang, Q.; Li, X.C.; Tian, Y.G.; Lin, Q.Q.; Xie, H.; Lu, W.B.; Chi, Y.G.; Chen, D.F. Lyophilized aqueous extracts of Mori Fructus and Mori Ramulus protect Mesenchymal stem cells from $\bullet \mathrm{OH}$-treated damage: Bioassay and antioxidant mechanism. BMC Complement. Altern. Med. 2017, 16, 423. [CrossRef] [PubMed]

35. Maciel, E.; Almeida, S.; da Silva, S.; de Souza, G. Examining the reaction between antioxidant compounds and 2,2-diphenyl-1-picrylhydrazyl (DPPH•) through a computational investigation. J. Mol. Model. 2018, 24. [CrossRef]

36. Boudier, A.; Tournebize, J.; Bartosz, G.; El Hani, S.; Bengueddour, R.; Sapin-Minet, A.; Leroy, P. High-performance liquid chromatographic method to evaluate the hydrogen atom transfer during reaction between 1,1-diphenyl-2-picryl-hydrazyl radical and antioxidants. Anal. Chim. Acta 2012, 711, 97-106. [CrossRef]

37. Shang, Y.J.; Qian, Y.P.; Liu, X.D.; Dai, F.; Shang, X.L.; Jia, W.Q.; Liu, Q.; Fang, J.G.; Zhou, B. Radical-scavenging activity and mechanism of resveratrol-oriented analogues: Influence of the solvent, radical, and substitution. J. Org. Chem. 2009, 74, 5025-5031. [CrossRef]

38. Li, X.; Xie, Y.; Xie, H.; Yang, J.; Chen, D. $\pi-\pi$ Conjugation Enhances Oligostilbene's Antioxidant Capacity: Evidence from $\alpha$-Viniferin and Caraphenol A. Molecules 2018, 23, 694. [CrossRef]

39. Li, X.; Xie, H.; Zhan, R.; Chen, D. Effect of Double Bond Position on 2-Phenyl-benzofuran Antioxidants: A Comparative Study of Moracin C and Iso-Moracin C. Molecules 2018, 23, 754. [CrossRef]

40. Lin, J.; Li, X.C.; Chen, L.; Lu, W.Z.; Chen, X.W.; Han, L.; Chen, D.F. Protective effect against hydroxyl radical-induced DNA damage and antioxidant mechanism of [6]-gingerol: A Chemical Study. B. Korean Chem. Soc. 2014, 35, 1633-1638. [CrossRef]

41. Tian, Y.; Li, X.; Xie, H.; Wang, X.; Xie, Y.; Chen, C.; Chen, D. Protective Mechanism of the Antioxidant Baicalein toward Hydroxyl Radical-Treated Bone Marrow-Derived Mesenchymal Stem Cells. Molecules 2018, 23, 223. [CrossRef] [PubMed]

42. Li, X.; Mai, W.; Chen, D. Chemical Study on Protective Effect Against Hydroxyl-induced DNA Damage and Antioxidant Mechanism of Myricitrin. J. Chin. Chem. Soc. 2014, 61, 383-390. [CrossRef]

43. Xie, Y.; Li, X.; Chen, J.; Deng, Y.; Lu, W.; Chen, D. pH Effect and Chemical Mechanisms of Antioxidant Higenamine. Molecules 2018, 23, 2176. [CrossRef] [PubMed]

Sample Availability: Sample of the compound echinatin is available from the authors. 